\title{
Dampak Moderasi Locus of Control terhadap \\ Efektivitas Sistem Informasi Keuangan pada Kantor Kecamatan di \\ Kota Semarang, Provinsi Jawa Tengah
}

\author{
Rohma Septiawati $^{1 *}$, Devi Astriani ${ }^{2}$, Kiryanto ${ }^{3}$ \\ ${ }^{1)}$ Program Studi Akuntansi, Fakultas Ekonomi dan Bisnis, Universitas Buana Perjuangan Karawang, rohmaseptiawati@ubpkarawang.ac.id. \\ ${ }^{2)}$ Program Studi Akuntansi, Fakultas Ekonomi dan Bisnis, Universitas Buana Perjuangan Karawang, Semarang,devi.astriani@ubpkarawang.ac.id \\ ${ }^{3)}$ Program Studi Akuntansi, Fakultas Ekonomi dan Bisnis, Universitas Islam Sultan Agung, Semarang, kiryanto_fe@yahoo.co.id
}

\section{ARTICLE INFO}

\section{Article history:}

Received 14 Maret 2021

Received in Revised 17 April 2021

Accepted 29 April 2021

Keywords:

top management, user satisfaction, organizational culture, locus of control, financial information systems
ABSTRACT

The purpose of this study was to analyze the impact of locus of control moderation, the factors that affect the financial information system at the subdistrict office in the city of Semarang. This study's population was 16 Districts Offices in Semarang City and obtained 54 questionnaires, then analyzed moderating regression analysis (MRA). From the research results of the impact of Locus of Control Moderation on the Effectiveness of Financial Information Systems at the District Office in Semarang City, Central Java Province, the results of the research on the first hypothesis, the influence of top management on the effectiveness of information systems, are to examine the influence of user satisfaction on the effectiveness of information systems, to examine the influence of organizational culture on the effectiveness of information systems. The effectiveness of information systems, to examine the effect of locus of control on the relationship between top management on the effectiveness of information systems, to examine the effect of locus of control between user satisfaction on the effectiveness of information systems from the results of the research resulted that it has a positive and significant effect.

Tujuan penelitian ini adalah untuk menganalisis pengaruh moderasi locus of control, faktor-faktor yang mempengaruhi sistem informasi keuangan pada kantor kecamatan di kota Semarang. Populasi penelitian ini adalah 16 Kantor Kecamatan di Kota Semarang dan diperoleh 54 kuesioner, kemudian dianalisis analisis regresi moderasi (MRA). Dari hasil penelitian pengaruh Locus of Control Moderation terhadap Efektifitas Sistem Informasi Keuangan pada Kantor Kecamatan Kota Semarang Provinsi Jawa Tengah diperoleh hasil penelitian hipotesis pertama yaitu pengaruh manajemen puncak terhadap efektivitas sistem informasi, untuk menguji pengaruh kepuasan pengguna terhadap efektivitas sistem informasi, untuk menguji pengaruh budaya organisasi terhadap efektivitas sistem informasi. Efektivitas sistem informasi, untuk menguji pengaruh locus of control terhadap hubungan antara manajemen puncak terhadap efektivitas sistem informasi, untuk menguji pengaruh locus of control antara kepuasan pengguna terhadap efektivitas sistem informasi dari hasil penelitian menghasilkan pengaruh yang positif dan signifikan.

\section{AKUISISI : Jurnal Akuntansi}

Website : http://www.fe.ummetro.ac.id/ejournal/index.php/JA

This is an open access article distributed under the terms of the Creative Commons Attribution 4.0 International License, which permits unrestricted use, distribution, and reproduction in any medium, provided the original work is properly cited. 


\section{PENDAHULUAN}

Kehadiran teknologi komputer dan informasi dalam organisasi saat ini telah berkembang secara dramatis. Sampai sekarang sejak tahun 1980-an, Menurut Westland dan Clark (2000), sekitar 50 persen dari seluruh investasi modal baru dalam organisasi dalam bentuk teknologi informasi (Venkatesh, et.al. 2003). Menurut Nugroho Widjajanto (2001), perlunya sistem akuntansi yang efisien dan efektif dalam melaksanakan kegiatan sektor publik atau perusahaan yang secara khusus menyajikan informasi yang sesuai dengan kebutuhan manajemen maupun berbagai pihak lainnya (Hidayati, 2017). Adanya inovasi perangkat teknologi informasi baik hardware maupun software yang memiliki kompleksitas tersendiri menjadi bagian yang tidak dapat dipisahkan dari suatu organisasi, sehingga menjadi tantangan multidimensi bagi manajemen perusahaan khususnya di negara berkembang (Husain, 2017). Oleh karena itu, pentingnya pengelolaan sistem informasi dalam kerangka kerja akuntansi guna mengolah informasi dan membantu mempermudah manajemen dalam pengambilan keputusan bisnis.

Menurut Romney \& Steinbart (2018:10) sistem informasi akuntansi adalah sistem yang dapat mengumpulkan, mencatat, menyimpan, dan memproses data untuk menghasilkan informasi bagi para pembuat keputusan. Pengembangan sistem informasi berarti mengubah teknologi informasi yang digunakan oleh organisasi. Perubahan tersebut pasti menimbulkan akibat positif, maupun negatif, akibat positifnya tentu adalah makin efisiennya kegiatan organisasi, sedangkan akibat buruknya kemungkinan besar, sumber daya yang ada di dalam organisasi tidak siap dengan perubahan teknologi (Wijayanti, 2005), kondisi tersebut maka proses pekerjaan yang dilakukan menggunakan teknologi informasi tidak dapat berjalan secara maksimal Efektivitas sistem informasi akuntansi sangat tergantung pada keberhasilan kinerja antara sistem, pemakai (user), dan sponsor.

Faktor-faktor penting yang dapat mempengaruhi efektivitas sistem informasi akuntansi diharapkan dapat memberikan pengaruh posistif yang dapat menunjukan tingkat keberhasilan sistem dalam menjalankan fungsinya (Ratnaningsih \& Suaryana, 2014). Di samping itu, fungsi pengukuran pengambilan keputusan dalam output laporan keuangan lazimnya menggunakan komponen seperti laporan keuangan dan kesepakatan antara agent dan principal dalam pemilihan perangkat kebijakan akuntansi (Husain \& Wahyudi, 2020). Dalam pencapaian pengefektivan teknologi informasi dalam kantor-kantor pemerintah sektor publik menghadapi banyak tantangan atau kendala. Hal tersebut dikarenakan struktur birokrasi kelemahan dalam pekerjaan akuntabilitas IT, hubungan pertanggung jawaban yang lemah, pekerjaan IT yang rumit dan membingungkan yang masih dalam pembelajaran IT. Efektivitas organisasi publik dalam konteks di Delhi India ditentukan oleh beberapa faktor antara lain manajemen puncak (top management), Manajemen SI, budaya organisasi, kepuasan pengguna dan penggunaan SI (Gupta, et.al. 2007). dukungan manajemen puncak merupakan kegiatan yang 
berdampak, mengarahkan dan menjaga perilaku manusia yang ditunjukkan oleh direktur, presiden, kepala divisi dan sebagainya dalam organisasi (Dewi \& Dwiandra, 2013). Manajemen puncak terlibat dalam proyek-proyek pengambilan keputusan yang berkaitan dengan SI profesional dan pengguna didalam organisasi, adapun diperlukan komunikasi perkenalan sosialisasi yang lebih baik antara manajemen puncak mendukung adanya proses perkembangan pekerjaan IT yang melibatkan karyawan disemua tingkat dan meningkatkan kepercayaan diantara karyawan yang akan menghasilkan hasil yang lebih baik saat pengambilan keputusan (Gupta, et.al. 2007).

Gudela Grote dan Christof Baitsch (1991), dalam perihal pengaruh timbal balik antara budaya organisasi dan implementasi pada office managament sistem, menemukan bahwa teknologi tidak mempengaruhi suatu perubahan dalam budaya, tetapi teknologi sendirilah yang terintegrasi ke dalam pola budaya, dengan temuan bahwa teknologi informasi atau dalam ruang lingkup yang lebih luas, sistem informasi adalah suatu sistem budaya, hal ini menyebabkan optimalisasi penggunaan TI juga sangat ditentukan oleh aspek budaya. Dengan demikian, riset mengenai aspek budaya dalam SI atau TI menjadi penting (Satria, 2008). Gupta et al. (2007), di dalam penelitiannya menghasilkan temuan atas kendala mengenai kurangnya pelatihan dan pemahaman sistem informasi antara manajemen puncak hal tersebut merupakan masalah terbesar dalam efektivitas IT dalam organisasi. Hasil penelitian yang menunjukkan bahwa semakin besar tingkat kepuasan pemakai maka akan semakin besar pula tingkat kinerja sistem informasi yang dihasilkan, peningkatan kepuasan pemakai dapat meningkatkan kinerja sistem (Wijayanti, 2005).

Locus of control menggambarkan seberapa jauh seseorang memandang hubungan antara perbuatan yang dilakukan (action) dengan akibat/hasil (outcome). Locus of control berhubungan dengan sikap kerja dan citra diri seseorang. Dari kutipan di atas Locus of control didalam organisasi merupakan pendorong atau pelemah untuk efektivitas pada sistem informasi pada suatu organisasi (Schultz \& Schultz, 2016). Sistem informasi manajemen merupakan suatu proses yang akan menghasilkan suatu output berupa informasi. Sementara itu struktur organsiasi akan menentukan suatu output berupa informasi. Sementara itu Struktur Organisasi akan menentukan bagaimana arus informasi tersebut dalam suatu organisasi. Sistem Informasi Manajemen dan Struktur Organisasi akan mempengaruhi efektivitas pengambilan keputusan (Rahmadana \& Bijaksana, 2002). Penelitian dengan temuan atas semakin tinggi kapasitas individu berhubungan dengan semakin meningkatnya budgetary slack, apabila manajer pembuat anggaran tersebut cenderung memiliki locus of control internal. Sebaliknya apabila manajer pembuat anggaran memiliki locus of control eksternal, kapasitas individu tidak begitu tinggi dan budgetary slack kemungkinan juga akan menurun (Sari, 2006).

Penelitian ini merupakan penelitian replikasi dari penelitian Gupta, et.al. (2007), dimana penelitian didasarkan Sistem Informasi pada Organisasi Sektor Publik di India tepatnya di New Delhi 
dan penelitian (Satria, 2008) pada Organisasi Publik di Surakarta dan beberapa jurnal di atas. Peneliti mengambil berkaitan dengan manajemen puncak, kepuasan penggunaan sistem informasi dan budaya organisasi selain obyek penelitian ada penambahan variabel moderasi yaitu locus of control hasil penelitian oleh Shinta Permatasari (2006), oleh karena itu penelitian ini diuji kembali pada Kantor Kecamatan di Kota Semarang Provinsi Jawa Tengah. Locus of control menggambarkan tingkat keyakinan seseorang tentang sejauh mana mereka dapat mengendalikan faktor-faktor yang memengaruhi keberhasilan atau kegagalan dalam dirinya.

\section{TINJAUAN PUSTAKA}

Sistem informasi akuntansi adalah sistem yang dapat mengumpulkan, mencatat, menyimpan, dan memproses data untuk menghasilkan informasi bagi para pembuat keputusan. Hal ini termasuk orang, prosedur dan instruksi, data, perangkat lunak, infrastruktur teknologi informasi, kontrol internal serta langkah-langkah keamanan (Romney \& Steinbart, 2018, p. 10). Manajemen puncak memiliki kewajiban merencanakan kegiatan dan strategi perusahaan secara umum dan mengarahkan jalannya organisasi atau perusahaan. Banyak perusahaan-perusahaan yang mencoba mengembangkan usahanya dan mencoba meraih pangsa pasar seluas-luasnya. Untuk mengembangkan usaha tentu hal ini tidak lepas dari unsur permodalan baik (Hendri, 2015). Robert L. Katz (1970) mengemukakan bahwa setiap manajer membutuhkan minimal tiga keterampilan dasar. Ketiga keterampilan tersebut adalah; 1. keterampilan konseptual (conceptional skill), 2. keterampilan berhubungan dengan orang lain (humanity skill), dan 3) keterampilan teknis (technical skill).

Menurut Bailey dan Pearson (1983), kepuasan pengguna sering digunakan untuk menunjukkan kesuksesan suatu sistem informasi yang berhubungan dengan kesuksesan konstruksi dalam sebuah ukuran jumlah dari konseptual dan aspek empirik. Menurut Ives, Olson dan Baroudi (1983), kepuasan pengguna adalah sebuah fungsi dari karakteristik sistem untuk mengetahui seberapa jauh informasi yang disediakan dapat memenuhi kebutuhan informasi yang mereka butuhkan (Astuti, 2003). Menurut DeLone \& McLean (2003), kepuasan yang merujuk pada respon pengguna terhadap output dari sistem informasi (Husain, 2020). Menurut Edgar H. Schein (1992:16), budaya organisasi adalah pola dasar yang diterima oleh organisasi untuk bertindak dan memecahkan masalah, membentuk karyawan yang mampu beradaptasi dengan lingkungan dan mempersatukan anggotaanggota organisasi maka diperlukan ajaran cara yang benar untuk mengkaji, berfikir dan merasakan masalah yang dihadapi (Tehangga, 2017). Budaya organisasi juga merupakan suatu persepsi bersama yang dianut oleh anggota-anggota organisasi itu (Robbins \& Coulter, 2016).

Peter Brownell (1982), locus of control menggambarkan tingkat keyakinan seseorang tentang sejauh mana mereka dapat mengendalikan faktor-faktor yang memengaruhi keberhasilan atau 
kegagalan dalam dirinya (Jayanti, Sujana, \& Wahyuni, 2017). Peter Brownell mengelompokkan berbagai kondisi kedalam empat kelompok variabel, yaitu: kultural, organisasional, interpersonal dan individual. Locus of control merupakan salah satu faktor individual yang mempengaruhi cara pandang seseorang terhadap suatu peristiwa, bisa tidaknya ia mengendalikan peristiwa tersebut. Ciriciri Locus of control yaitu:

1) Locus of control merupakan suatu konsep yang menunjuk pada keyakinan individu mengenai peristiwa-peristiwa yang terjadi dalam hidupnya,

2) Locus of control menggambarkan seberapa jauh seseorang memandang hubungan antara perbuatan yang dilakukan (action) dengan akibat/hasil (outcome),

3) Locus of control berhubungan dengan sikap kerja dan citra diri seseorang (Schultz \& Schultz, 2016).

\section{Model Penelitian}

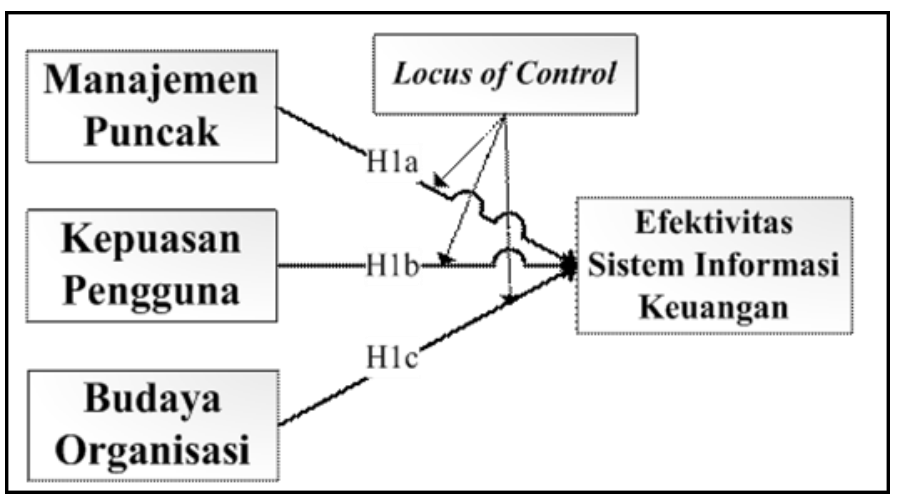

\section{METODELOGI}

Jenis penelitian ini merupakan eksplanatori (explanatory research) yang bertujuan dalam menguji variabel yang dihipotesiskan diantaranya untuk membuktikan kebenarannya. Hipotesis ini menggambarkan asosiasi antar variabel apakah variabel penyebab dipengaruhi atau tidak oleh variabel lainnya (Sani \& Maharani, 2013). Jenis penelitian dengan pendekatan survei dilakukan ke tempat lokasi dengan menggunakan metode kuantitatif data primer dan sekunder maka dilakukan penyebaran kuesioner sebagai data deskriptif guna menguji hipotesis dan model analisis. Respondennya dalam kuesioner ini adalah pegawai bagian Sistem Informasi Keuangan kantor Kecamatan Kota Semarang. Populasi dalam penelitian ini adalah pegawai sistem informasi keuangan (kasubag keuangan, bendahara gaji, bendahara pengeluaran, dan pembuku keuangan) pada kantor seluruh Kecamatan Kota Semarang yang berjumlah 16 (enam belas) Kecamatan. 


\section{Variabel dan Indikator Penelitian}

\begin{tabular}{|c|c|c|}
\hline Variabel & Indikat & Pengukura \\
\hline $\begin{array}{l}\text { Manajemen } \\
\text { Puncak }\end{array}$ & $\begin{array}{l}\text { 1. Persetujuan dan pengambilan } \\
\text { keputusan dalam organisasi } \\
\text { 2. Persaingan dari luar organisasi } \\
\text { 3. Bantuan sistem informasi }\end{array}$ & $\begin{array}{r}\text { Skala } \\
\text { Likert } \\
.1 \mathrm{~s} / \mathrm{d}\end{array}$ \\
\hline $\begin{array}{l}\text { Kepuasan } \\
\text { Pengguna }\end{array}$ & $\begin{array}{l}\text { 1. Kesesuaian penggunaan } \\
\text { Sistem Informasi } \\
\text { keuangan antuk } \\
\text { mendukung pekerjaan } \\
\text { 2. }\end{array}$ & $\begin{array}{l}\text { Skala } \\
\text { Likert } \\
, 1 \mathrm{~s} / \mathrm{d}\end{array}$ \\
\hline $\begin{array}{l}\text { Budaya } \\
\text { Organisasi }\end{array}$ & $\begin{array}{l}\text { 1. Penghargaan dan rasa } \\
\text { aman dalam } \\
\text { menjalankan } \\
\text { pekerjaan } \\
\text { 2. Penghargaan penggunaan } \\
\text { sistem informasi } \\
\text { 3. Perbedaan, setiap devisi } \\
\text { menentukan aturannya sendiri }\end{array}$ & $\begin{array}{l}\text { Skala } \\
\text { Likert } \\
, 1 \mathrm{~s} / \mathrm{d} \\
9\end{array}$ \\
\hline $\begin{array}{l}\text { Efektivitas } \\
\text { Sistem } \\
\text { Informasi }\end{array}$ & $\begin{array}{l}\text { 1. Efektivitas dan produktivitas } \\
\text { pekerjaan } \\
\text { 2. Komunikasi } \\
\text { 2. Kualitas nenoamhilan }\end{array}$ & $\begin{array}{l}\text { Skala } \\
\text { Likert }\end{array}$ \\
\hline $\begin{array}{l}\text { Locus of } \\
\text { Control }\end{array}$ & $\begin{array}{l}\text { Kebebasan bawahan dalam } \\
\text { berpendapat } \\
\text { 2. Sistem informasi keuangan } \\
\text { pada pekerjaan yang cepat } \\
\text { dan efektif } \\
\text { 3. Penghargaan untuk pegawai }\end{array}$ & $\begin{array}{l}\text { Skala } \\
\text { Likert } \\
, 1 \mathrm{~s} / \mathrm{d} \\
5\end{array}$ \\
\hline
\end{tabular}

\section{HASIL PENELITIAN DAN PEMBAHASAN}

$\mathrm{H}_{1} \mathrm{a}$ : Hasil pengujian menunjukkan bahwa manajemen puncak memiliki pengaruh positif yang signifikan terhadap efektivitas SIK. Hal ini berarti bahwa semakin besar dukungan dari manajemen puncak akan memperbesar efektvitas SIK yang ada Hal ini menjelaskan bahwa faktor sosial yang berupa dukungan dari manajemen dalam pengggunaan sistem informasi dalam terciptanya pemanfaatan yang lebih besar. Hal ini menjelaskan bahwa pengembangan dan pemanfaatan teknologi informasi harus melibatkan partisipasi dan dukungan manajemen.

$\mathrm{H}_{2} \mathrm{~b}$ : Hasil pengujian menunjukkan bahwa kepuasan pengguna memiliki pengaruh terhadap efektivitas SIK dengan arah positif. Hal ini berarti bahwa semakin besar kondisi perasaan puas dari pengguna terhadap sistem informasi keuangan yang digunakan maka akan semakin besar dalam terciptanya efektivitas dari pemanfaatan sistem informasi tersebut.

$\mathrm{H}_{3} \mathrm{c}$ : Hasil pengujian menunjukkan bahwa budaya organisasi memiliki pengaruh terhadap efektivitas sistem informasi keuangan (SIK) dengan arah positif. Hal ini berarti bahwa semakin sesuai 
budaya organisasi yang ada akan berdampak pada pemanfaatan TI yang semakin besar sehingga efektivitas SIK semakin tinggi.

H2 : Hasil pengujian menunjukkan bahwa locus of control(LOC) memiliki pengaruh dalam memoderasi hubungan manajemen puncak dengan efektivitas SIK dengan arah positif. Hal ini berarti bahwa banyaknya pegawai dengan internal locus of control(LOC) akan semakin meningkatkan dukungan manajemen puncak dalam pemanfaatan SIK. Hasil pengujian menunjukkan bahwa locus of control memiliki pengaruh dalam memoderasi hubungan kepuasan pemakai dengan efektivitas SIK dengan arah positif. Hal ini berarti bahwa banyaknya pegawai dengan internal akan semakin meningkatkan pengaruh kepuasan pemakai terhadap efektivitas SIK.

\section{KESIMPULAN}

Semakin besar dukungan manajemen puncak dalam organisasi akan meningkatkan efektivitas SIK. Semakin besar kepuasan pemakai dalam organisasi akan meningkatkan efektivitas SIK. Semakin besar kesesuaian budaya organisasi dalam organisasi akan meningkatkan efektivitas SIK. Locus of control dapat meningkatkan pengaruh manajemen puncak terhadap efektivitas SIK. Pengguna sistem dengan locus of control internal akan meningkatkan pengaruh dukungan manajemen puncak dalam organisasi terhadap efektivitas SIK. Locus of control dapat meningkatkan pengaruh kepuasan pemakai terhadap efektivitas SIK. Pengguna sistem dengan LOC internal akan meningkatkan pengaruh kepuasan pemakai dalam organisasi terhadap efektivitas SIK.

Keterbatasan yang ada dalam penelitian ini adalah sebagai berikut :

1. Penelitian ini tidak memisahkan pengguna sistem yang terdidik atau terlatih dengan tidak memisahkan pemakai sistem dari tingkat pendidikannya sebagai variabel kontrol.

2. Hasil penelitian ini koefisien determinasi (adjusted $\mathrm{R}^{2}$ ) hanya menunjukkan nilai sebesar 55,2 persen hal ini menunjukkan bahwa 44.8 persen dipengaruhi variabel lain maka penelitian selanjutnya diharapkan bisa menambah variabel lain misalnya pendidikan atau variabel pengalaman pada penelitiannya.

3.

\section{DAFTAR PUSTAKA}

Astuti, S. (2003). Pengaruh Diversitas Kemanfaatan dan Lingkup Pengembangan Kemanfaatan Tehnologi Informasi terhadap Kepuasan Pemakai. Kompak, 7, 94-117.

Bailey, J. A., \& Pearson, S. W. (1983). Development of a Tool for Measuring and Analyzing Computer User Satisfaction. Management Science, 29(5), 530-545. 
Brownell, P. (1982). A Field Study Examination of Budgetary Participation and Locus of Control. The Accounting Review, 57(4), 766-777.

Dewi, S. A., \& Dwiandra, A. (2013). Pengaruh Dukungan Manajemen Puncak, Kualitas Sistem, Kualitas Informasi, Pengguna Aktual Dan Kepuasan Pengguna Terhadap Implementasi Keuangan Daerah Di Kota Denpasar. E-Jurnal Akuntansi, 4(1), 196-214.

Ghozali, I., \& Ratmono, D. (2017). Analisis Multivariat dan Ekonometrika: Teori, Konsep, dan Aplikasi dengan EViews 10 (Cetakan II) (2 ed.). (A. Tejokusumo, Ed.) Semarang: Badan Penerbit Universitas Diponegoro.

Grote, G., \& Baitsch, C. (1991). Reciprocal effects between organizational culture and the implementation of an office communication system: a case study. Behaviour \& Information Technology, 10(3), 207-218.

Gupta, et.al. (2007). A Study of Information Technology Efectiveness in Select Government Organizations in India. Vikalpa: The Journal of Decision Makers, 32(2), 7-21.

Hendri, N. (2015). Analisis Faktor-faktor Yang Mempengaruhi Audit Delay Pada Perusahaan Go Public Di Bursa Efek Indonesia Tahun 2010-2013. Akuisisi: Jurnal Akuntansi , 11 (1).

Hidayati. (2017). Analisis Kualitas Penerapan SIA, Pemanfaatan dan Kepercayaan terhadap Teknologi Informasi pada Dinas Pangan dan Perkebunan Kabupaten Melawi. Jurnal Mahasiswa Akuntansi, 6(4).

Husain, T. (2017). Analisis Determinan Faktor-Faktor Yang Mempengaruhi Niat Penggunaan Software Audit. Jurnal Ilmiah Matrik, 19(2), 131-150.

Husain, T. (2020). Analisis Keberhasilan Penerapan Sistem RFID Terintegrasi (Studi tentang EndUser's Kartu e-Toll di Tol JORR 2). JUSIM (Jurnal Sistem Informasi Musirawas), 05(02), 124-133.

Husain, T., \& Wahyudi, R. (2020). Audit Quality Intercession: Financial Ratios and Firm's Value. ADVANCE, 7(1), 1-14.

Ives, B., Olson, M. H., \& Baroudi, J. J. (1983). The measurement of user information satisfaction. Communications of the ACM, 26(10).

Jayanti, N. R., Sujana, E., \& Wahyuni, M. A. (2017). Pengaruh Locus Of Control, Komitmen Profesional dan Stres Kerja terhadap Reduksi Kualitas Audit (Studi Empiris pada Kantor Akuntan Publik di Bali). e-Journal S1 Akuntansi, 7(1).

Mintzberg, H. (1973). The Nature of Managerial Work: Harper \& Row. New York

Rahmadana, M. F., \& Bijaksana, W. (2002). “ Pengaruh System Informasi Manajemen dan Struktur Organisasi Terhadap Efektivitas Pengambilan Keputusan Pada Kantor Pelayanan Bea dan Cukai Tipe A Belawan. Jurnal Ilmiah “Manajemen \& Bisnis”, 02(02), 37.

Ratnaningsih, K. I., \& Suaryana, I. G. (2014). Pengaruh Kecanggihan Teknologi Informasi, Partisipasi Manajemen, dan Pengetahuan Manajer Akuntansi pada Efektivitas Sistem Informasi Akuntansi. E-Jurnal Akuntansi, 6(1), 1-16. 
Robbins, S. P., \& Coulter, M. (2016). Manajemen (Jilid 1 dan 2) (13 ed.). (B. Sabran, \& W. Hardani, Trans.) Jakarta: Erlangga.

Romney, M. B., \& Steinbart, P. J. (2018). Accounting Information Systems (14 ed.). New York: Pearson.

Sani, A., \& Maharani, V. (2013). Metodologi Penelitian Manajemen Sumber Daya Manusia (Teori, Kuesioner dan Analisis Data), Cetakan Ke-2. Malang: UIN MALIKI Press.

Sari, S. P. (2006). Pengaruh Kapasitas Individu yang Diinteraksikan Locus of Control terhadap Budgetary Slack. Simposium Nasional Akuntansi 9 (SNA IX), 23-26 Agustus 2006, (pp. KAMEN 07). Padang.

Satria, R. (2008). Penelitian Aspek Budaya pada Sistem Informasi. Jurnal Sistem Informasi (Journal of Information System), 4(1), 55-58.

Schultz, D., \& Schultz, S. E. (2016). Psychology and Work Today (10 ed.). New York: Pearson Education, Inc.

Tehangga, T. (2017). Pengaruh Budaya Sekolah terhadap Kecerdasan Spiritual Siswa di SMA Negeri 1 BONDOALA. Sulawesi Tenggara: IAIN Kendari.

Venkatesh, et.al. (2003). User Acceptance of Information Technology: Toward A Unified View. MIS Quarterly, 27(3), 425-478.

Wijayanti, L. E. (2005). Pengaruh Perilaku Pemakai Terhadap Kinerja Sistem Informasi: Partisipasi dan Kepuasan Pemakai Sebagai Variabel Independen. Jurnal Pendidikan Akutansi Indonesia, III(2), 24-35. 